\title{
Percutaneous compression plating versus gamma nail for the treatment of pertrochanteric hip fractures
}

\author{
Rinaldo Giancola • Guido Antonini · \\ Giacomo Delle Rose · Cornelio Crippa
}

Received: 16 September 2007/ Accepted: 21 January 2008/Published online: 29 March 2008

(C) Springer-Verlag 2008

\begin{abstract}
The objective of this study is to compare percutaneous compression plating (PCCP) device with standard gamma nail (GN). A sample was prospectively followed and compared to a historical cohort: 82 intertrochanteric hip fractures in 81 patients treated with PCCP in 2004 versus 51 hip fractures treated with GN in 2003 (AO type $31 \mathrm{~A} 1,31 \mathrm{~A} 2)$. The main outcome measures were: surgery times, blood loss (Hb serum level and transfusions), complication, costs, for a 1-year follow-up. The minimally invasive PCCP technique resulted in a lower blood loss and consequently lower transfusion need (statistically significant), fewer implant-related complications and comparable surgery times. Overall surgical costs were lower for a comparable outcome in terms of healing and surgical time.
\end{abstract}

Keywords Hip fracture - Pertrochanteric fracture . Minimally invasive - Percutaneous - Fracture fixation . Percutaneous compression plate

R. Giancola · G. Antonini - G. Delle Rose · C. Crippa Orthopaedic and Trauma Departement, Azienda Ospedaliera San Carlo Borromeo, Via Pio II, 3, 20153 Milan, Italy

R. Giancola $(\bowtie)$

Via Matteo Bandello, 220123 Milan (MI), Italy

e-mail: Giancola.Rinaldo@sancarlo.mi.it

G. Antonini

Via Forlì, 19, 20036 Meda (MI), Italy

e-mail: md.guidoantonini@gmail.com

G. Delle Rose

Via Gramsci Antonio, 18, 20047 Brugherio (MI), Italy

C. Crippa

Via De Leyva, 11, 20052 Monza (MI), Italy

e-mail: elio.crippa@tiscali.it

\section{Introduction}

The treatment of pertrochanteric fractures in the elderly is a source of debate when the costs associated with this injury are increasing as is life expectancy in the population [1-5]. New devices are being developed for the osteosynthesis of these fractures and one of these is the PCCP (PerCutaneous Compression Plate; Orthofix SRL, Italy) [6-11]. This device is indicated for the treatment of pertrochanteric and basicervical fractures with intact lateral walls (AO types 31A1,31A2,B2.1) [12] and is inserted by a minimally invasive technique which minimizes soft tissue damage and blood loss, retains the fracture haematoma and avoids excessive periosteal stripping.

The device consists of a plate of a predetermined length with three diaphyseal screws and two telescopic cervical screws angled at $135^{\circ}$ to the plate to allow controlled fracture compression [13] (Fig. 1). We decided to evaluate the efficacy and possible advantages of this new device against the Gamma Nail (GN). This study prospectively recorded the operative and postoperative outcomes of a group of patients treated with the PCCP and compared this to a historical cohort stabilised with the Gamma Nail. There are no reports comparing the PCCP with an intramedullary device for these fractures in the literature.

\section{Materials and methods}

Inclusion criteria

The prospective study group consisted of patients that had been treated with the PCCP between January and 


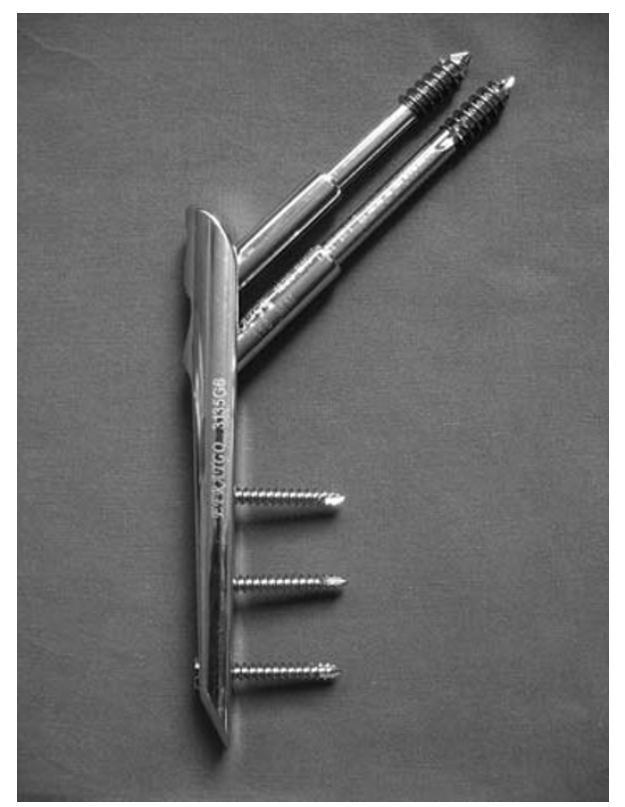

Fig. 1 The PCCP consists of a plate with a chisel end for percutaneous introduction, two telescoping self-cutting neck screws $\left(135^{\circ}\right)$ and three shaft screws

December 2004. The historical cohort consisted of patients that had been treated with the GN during 2003. The fracture types were $31 . \mathrm{A} 1$ and 31 .A2 for both the groups.

\section{Treatment}

Antithromboembolic prophylactic treatment with low molecular weight heparin (sodium enoxaparine or calcium nadroparine) and the antibiotic cephazolin were administered in a single dose 30 min before surgery.

The patient is positioned on a traction table in the operating theatre to obtain fracture reduction under Image Intensifier control. A transparent template of the device is then placed over the X-ray image of the proximal part of the femur to determine correct positioning of the plate and the cervical screws. Any posterior collapse of the fracture is corrected using the Posterior Reduction Device (PORD) as shown (Fig. 2). The plate is inserted through a carefully positioned lateral incision of approximately $2.5 \mathrm{~cm}$ which is deepened down to the femur. The plate is guided distally over the periosteum under the vastus lateralis muscle. A second $2.5 \mathrm{~cm}$ incision is made (Fig. 3) through which the first cervical screw is inserted, angled at $135^{\circ}$, followed by three bicortical diaphyseal screws and finally the second parallel cervical screw. No post-operative drainage is required.

The patient is allowed immediate full weight-bearing as tolerated after surgery and in accordance with their general medical condition.

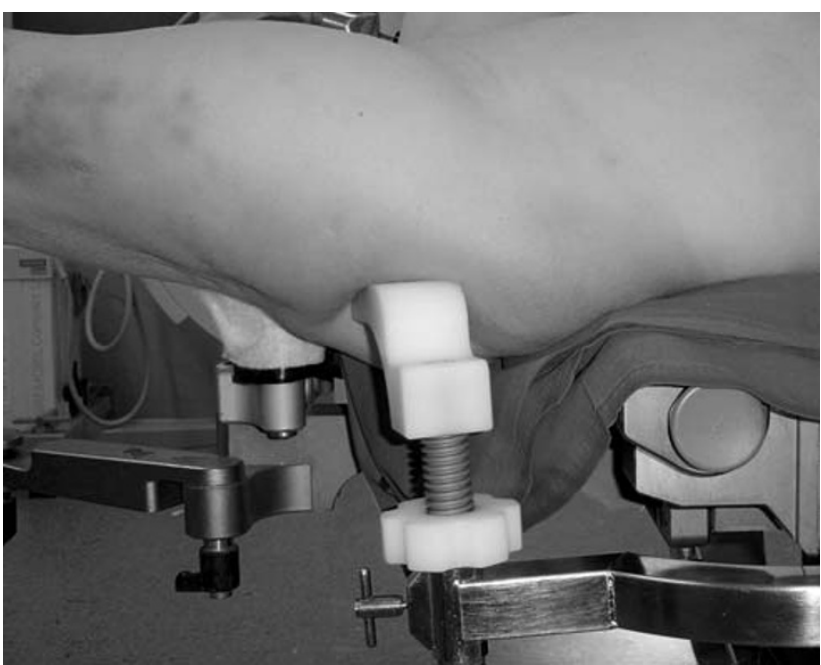

Fig. 2 PORD (posterior reduction device) a radiolucent apparatus for accurate reduction of posterior sagging

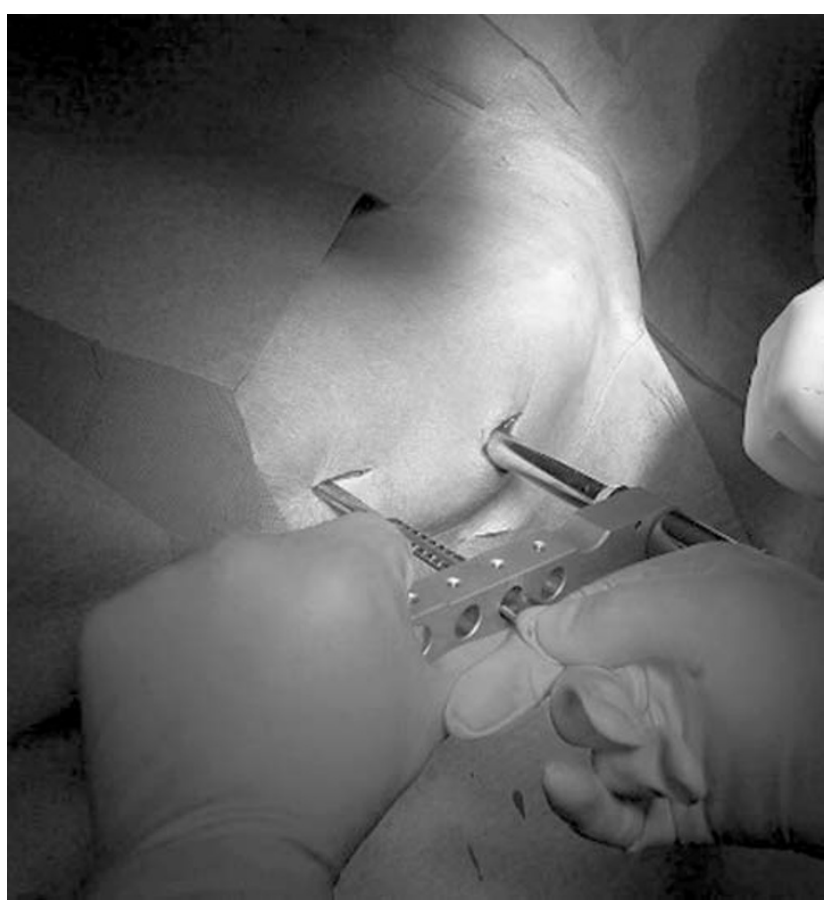

Fig. 3 Minimally invasive technique: two lateral incisions of approximately $2.5 \mathrm{~cm}$

\section{Data variables}

The following variables were collected: patient's age and sex, fracture type (AO classification), haemoglobin levels $(\mathrm{Hb})$ on admission and pre- and post-operatively, amount of pre- and post-operative blood transfusion, operation time, duration of hospital stay, intra- and post-operative complications, functional recovery, death rate and cost factors relating to the technique. 
Statistical analysis using the independent $t$-test and the $\chi^{2}$ test were applied to evaluate significant differences between the two groups ( $\alpha$ was set at 0.05 ).

\section{Results}

Patient population characteristics

The PCCP group consisted of 81 patients and 82 hips (one patient had a bilateral fracture) and the control group of 51 patients. The patient population characteristics are listed (Table 1): the average age was 81.1 (range 26-101) and 81.4 (range 34-97) years, respectively, for PCCP and GN groups.

The fractures were described according to the $\mathrm{AO}$ classification and are summarised (Table 2): in the PCCP group the percentage of A1 type fractures was similar to A2 (53\% vs. $47 \%)$; in the GN group the there is a lower percentage of A1 fractures.

Table 3 details the functional capacities of both groups before and after surgery. The two groups were not comparable in term of functional capacities. Fourteen percent of the GN group were not ambulatory before sustaining their fracture; $46 \%$ of this group were self sufficient compared with $77 \%$ of those in the PCCP group (Table 3).

Table 1 Patient population characteristics

\begin{tabular}{lll}
\hline & PCCP & Gamma nail \\
\hline Males & $19(24 \%)$ & $15(29 \%)$ \\
Females & $62(76 \%)$ & $36(71 \%)$ \\
Total & 81 & 51 \\
Mean age & 81.1 & 81.4 \\
Range (years) & $26-101$ & $34-97$ \\
\hline
\end{tabular}

Table 2 Fracture AO classification

\begin{tabular}{lcccccccc}
\hline & A1 & A1.1 & A1.2 & A1.3 & A2 & A2.1 & A2.2 & A2.3 \\
\hline PCC.P (\%) & 53 & 23 & 27 & 3 & 47 & 25 & 19 & 3 \\
GN (\%) & 36 & 27 & 6 & 3 & 63 & 24 & 30 & 9 \\
\hline
\end{tabular}

Table 3 Mobility before and after surgery

\begin{tabular}{lllll}
\hline & $\begin{array}{l}\text { Pre-op } \\
\text { gamma }\end{array}$ & $\begin{array}{l}\text { Pre-op } \\
\text { PCCP }\end{array}$ & $\begin{array}{l}\text { Post-op } \\
\text { gamma }\end{array}$ & $\begin{array}{l}\text { Post-op } \\
\text { PCCP }\end{array}$ \\
\hline Self-sufficient (\%) & 46 & 77 & 17 & 32 \\
Requiring help (\%) & 40 & 23 & 27 & 57 \\
Non-ambulatory (\%) & 14 & 0 & 56 & 11 \\
\hline
\end{tabular}

Surgery times

The average delay to surgery was 6.6 and 7.1 days for PCCP and GN groups respectively (NS, $P=0.443$ ), while post-operative hospitalisation was 14 and 15 days (NS, $P=0.999)$. Average surgery duration was determined from data taken from Operating Room registers and was 63 and $67 \mathrm{~min}$, respectively, for PCCP and GN groups (NS, $P=0.369)$.

In order to assess the influence of a learning curve for the technique, we compared the operation data of the PCCP from members of the surgical staff who had conducted more than eight procedures with the device. The average time of the first $50 \%$ of the operations for each surgeon were compared with times for subsequent operations. The average time saved was 17\% (range 6-28\%). Younger surgeons, although initially slower, later proved to have better time savings (Table 4).

Blood loss

The average $\mathrm{Hb}$ reading on admission was $12.1 \mathrm{~g} / \mathrm{dl}$ (PCCP) and $12.4 \mathrm{~g} / \mathrm{dl}(\mathrm{GN})(\mathrm{NS}, P=0.350)$. These values are often spurious as many patients arrive in Emergency Room in already precarious conditions and are frequently dehydrated. Patients were brought to the operating theatre with an average $\mathrm{Hb}$ of $11.4 \mathrm{~g} / \mathrm{dl}$ and $11.1 \mathrm{~g} / \mathrm{dl}$ (NS, $P=0.300$ ); these figures reflected the $22 \%$ (PCCP) and $14 \%$ (GN) of patients who had pre-operative transfusions before surgery. Changes in haemoglobin levels were calculated from differences in the pre-operative haemoglobin and a reading later that day or before a post-operative transfusion. Although the average haemoglobin levels just prior to transfusion of 8.3 and $8.6 \mathrm{~g} / \mathrm{dl}$ were not significantly different $(P=0.10)$, the average drop in haemoglobin levels post-surgery was 1.8 and $2.2 \mathrm{~g} / \mathrm{dl}$ for the two respective groups was $(P<0.05)$. The led to a significant difference observed in the numbers of units transfused between the two study groups. The PCCP group had 50\% fewer units of transfused blood. (0.9 units vs. 1.8 units, $P<0.0001)$. Furthermore $36 \%$ of patients treated with PCCP needed transfusions as compared with $79 \%$ of those that had GN surgery $(P<0.0001)$ (Table 5$)$.

Table 4 The "learning curve" for the technique

\begin{tabular}{lllllll}
\hline Surgeon & 1 & 2 & 3 & 4 & 5 & 6 \\
\hline $\begin{array}{l}\text { Average time for first } 50 \% \\
\text { of operations (min) }\end{array}$ & 71.7 & 70.0 & 65.0 & 65.6 & 56.7 & 80.0 \\
$\begin{array}{c}\text { Average time for second } 50 \% \\
\text { of operations (min) }\end{array}$ & 52.5 & 53.3 & 50.0 & 48.3 & 53.3 & 57.5 \\
\begin{tabular}{l} 
Percentage time saved \\
\hline
\end{tabular} & 26.7 & 23.8 & 23.1 & 26.3 & 5.9 & 28.1 \\
\hline
\end{tabular}


Table 5 The blood loss

\begin{tabular}{lllll}
\hline & $\begin{array}{l}\mathrm{Hb}(\mathrm{g} / \mathrm{dl}) \\
\text { pre-op. }\end{array}$ & $\begin{array}{l}\text { Hb drop } \\
\text { post-op. }\end{array}$ & $\begin{array}{l}\text { Number of } \\
\text { packed cell } \\
\text { units per person }\end{array}$ & $\begin{array}{l}\text { Patients } \\
\text { transfused } \\
\text { post-op. }(\%)\end{array}$ \\
\hline PCCP & 11.4 & 1.8 & 0.9 & 36 \\
GN & 11.1 & 2.2 & 1.8 & 79 \\
\hline
\end{tabular}

Peri-operative problems

For two patients in the PCCP group treatment had to be changed from PCCP to the GN due to failure to reduce the fracture. In both cases the patients were obese with posterior instability of the neck of the femur and the treating surgeon relatively inexperienced. In one patient screw cutout from the head of the femur occurred after 15 days due to a serious procedural error (the cephalic screws were positioned to the rear and protruded from the head of the femur).

There was one case of deep infection in a patient with metastatic breast cancer; the implant had to be removed.

There were no superficial infections, delays in healing or dehiscence of surgical wounds. There were also no recorded thromboembolic problems.

Intra-operative complications in the GN group involved rupture of the lateral wall in three patients and incorrect centering of the distal locking screw in one patient. There were no superficial or deep-seated infections nor problems with screw cut-out in this group.

\section{Follow-up}

Clinical comparisons were made at one year after surgery from case note and X-ray review (Fig 4). Function before and after trauma for both groups is shown (Table 4). Seventy-six of the PCCP cases (87\%) and 48 of the GN group (94\%) were reviewed. Mortality at one year was $9 \%$ in the PCCP patients (7 of 76) and $41 \%$ in the GN patients (20 of 48). This may reflect the difference in the patient groups before surgery and not the surgical technique applied.

\section{Surgery costs}

The difference in cost between the two implants is slightly in favour (by a few euros) of the PCCP If the unit cost (158 euro) [4] of erythrocyte concentrate is taken into consideration along with the average saving per person of 0.9 units, the overall annual savings total 12,371 euros for the 87 cases treated. Further small savings were made during this type of surgery from avoidance of electro-coagulation or need for post-operative drainage.

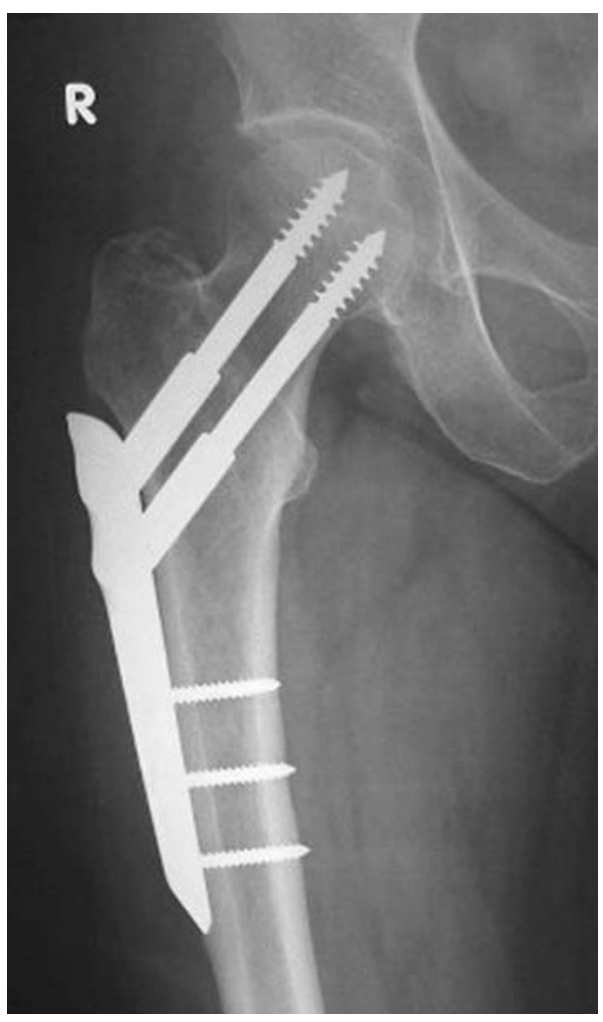

Fig. 4 Post-operative radiograph of pertrochanteric fracture treated with PCCP

\section{Discussion}

Patients' population characteristics

The characteristics of the patients' population studied are comparable with those of other studies presented in the literature $[6-9,11]$ in terms of age and sex. The fractures, defined by the inclusion criteria, included both A1 and A2 types and there were no differences in distribution between the groups even when split according to age or sex. There was however a difference in pre-injury function with a larger number of patients in the GN group in the nonambulatory category. This may explain the higher one year mortality in the GN group. The GN was also the preferred method for patients in poor pre-surgical clinical conditions in this hospital before the introduction of the PCCP (as surgeons were more accustomed to this technique and this in turn ensured shorter operating times). This bias may explain the higher number of A2 type fractures in GN group and is a consequence of using historical cohorts for comparative studies.

\section{Surgery times}

Hospitalisation times before surgery are the same for both groups. Operation times are in line with those published by 
other authors. The operative time in the literature varies from $67 \mathrm{~min} \mathrm{[11]} \mathrm{to} 46 \mathrm{~min}$ [6]. The average is similar for both groups in this study. There is an improvement in operation times with experience and, once the technique has been mastered, the average duration for surgery can be reduced to the region of $50 \mathrm{~min}$. Post-operative hospitalisation times are not related to the type of treatment received but to the availability of a place in a suitable rehabilitation centre.

\section{Blood loss}

The average haemoglobin level on admission demonstrates that patients may present with anaemia which is due to various factors ranging from the fracture itself to poor nutrition or other illnesses. In addition, the presenting haemoglobin level may be spuriously high because elderly patients are often dehydrated. One in five patients was given a transfusion preoperatively with no differences in the transfused units being observed between the two groups.

There were significant differences in post-operative transfusions. There were $50 \%$ fewer transfusions in the PCCP group. The average drop in haemoglobin level was $1.8 \mathrm{~g} / \mathrm{dl}$; this is lower than described in Kosygan's [9] report $(2.4 \mathrm{~g} / \mathrm{dl})$; however in terms of units transfused per person, the quantity of 0.9 is greater than that reported by Janzin (0.56) [8]. These results suggest that this minimally invasive method of fixation results in less blood loss and therefore fewer blood transfusions and correspondingly fewer attendant risks of transfusion reaction, infections and immunocompromise [14-16].

\section{Peri-operative problems}

The most likely reason in two patients in whom the PCCP was abandoned in favour of a GN was the learning curve of a new surgical technique. One event of cephalic screw cutout was also attributed to a procedural error.

In the GN group, rupture of the lateral wall had no effect upon fracture healing and the case with the non-centred screw was immediately rectified.

\section{Follow-up}

Inferences made on post-operative function and mortality are not valid owing to the dissimilarities between the groups pre-surgically in term of functional ability and type fracture. The PCCP group also had a lesser degree of anaemia.

Mortality in the PCCP group at one year was 9\% which is comparable to Gotfried (11.3\%) [7] but lower than Janzing (21\%) [8] or Peyser (16\%) [11]. Mortality was even lower when compared with published data which referred to the use of other techniques (Dzupa 30\% [17]; Chirodian 31\% [18]; Larsson 18\% [19]).

\section{Costs}

The new technique has the advantage of offering lower costs principally from the decreased number of transfusions required and to a lesser degree from avoidance of accessories (electro-coagulator and suction drain) used at surgery

\section{Conclusions}

The limitations of this study are the use of a historical cohort as the control group and the relatively small number of patients. The PCCP device appears to possess the advantage of being less invasive than the intramedullary nail technique. Surgery times are comparable to other currently used techniques but there is a suggestion that fewer transfusions may be needed after surgery, leading to reduced costs. Within the limits of such a study, the PCCP is therefore a viable alternative treatment for pertrochanteric fractures in the elderly. A randomized controlled trial would be needed to show if the conclusions reached here can be further supported.

\section{References}

1. Anderson GH, Raymakers R, Gregg PJ (1993) The incidence of proximal femoral fractures in an English county. J Bone Joint Surg Br 75(3):441-444

2. Gallagher JC, Melton LJ, Riggs BL et al (1980) Epidemiology of fractures of the proximal femur in Rochester. Minnesota Clin Orthop 150:163-171

3. Jensen JS (1980) Incidence of hip fracture. Acta Orthop Scand $51: 511-513$

4. Symposium (1993) Hip fractures in the elderly: the coming epidemic. AAOS Annual Meeting, San Francisco

5. Wallace WA (1983) The increasing incidence of fractures of the proximal femur: an orthopædic epidemic. Lancet 25:1413-1414

6. Brandt SE, Lefever S, Janzing HM, Broos PL, Pilot P, Houben BJ (2002) Percutaneous compression plating (PCCP) versus the dynamic hip screw for pertrochanteric hip fractures: preliminary results. Injury Jun 33(5):413-418

7. Gotfried Y (2000) Percutaneous compression plating of intertrochanteric hip fractures. J Orthop Trauma 14(7):490-495

8. Janzing HM, Houben BJ, Brandt SE, Chhoeurn V, Lefever S, Broos P, Reynders P, Vanderschot P (2002) The Gotfried PerCutaneous Compression Plate versus the Dynamic Hip Screw in the treatment of pertrochanteric hip fractures: minimal invasive treatment reduces operative time and post-operative pain. J Trauma 52(2):293-298

9. Kosygan KP, Mohan R, Newman RJ (2002) The Gotfried percutaneous compression plate compared with conventional/classic hip screw for the fixation of intertrochanteric fractures of the hip. J Bone Joint Surg Br 84(1):19-22 
10. Krasheninnikoff M, Gramkow J, Torholm C, Gotfried PC (1998) C.P: A new method for osteosynthesis of intertrochanteric fractures of the femur. Acta Orthop Scand 280(Suppl 1):30-31

11. Peyser A, Weil Y, Brocke L, Manor O, Mosheiff R, Liebergall M (2005) Percutaneous compression plating versus compression hip screw fixation for the treatment of intertrochanteric hip fractures. Injury 36(11):1343-1349

12. Muller ME, Allgower M, Willenegger H (1996) Manual of internal fixation. Berlin, Springer-Verlag, 1970. Orthopædic trauma association committee for coding and classification. Fracture and dislocation compendium. J Orthop Trauma 10(Suppl 1):31-34

13. Gotfried Y, Cohen B, Rotem A (2002) Biomechanical evaluation of the percutaneous compression plating system for hip fractures. J Orthop Trauma 16, 9:644-650

14. Dodd R (1992) The risk of transfusion-transmitted infection. N Engl J Med 327:419-421
15. Linden JV, Kaplan HS (1994) Transfusion errors: causes and effects. Transfus Med Rev 8:169-183

16. Perkins H (1988) Transfusion-induced immunologic unresponsivness. Transfus Med Rev 2:196-203

17. Dzupa V, Bartonicek J, Skala-Rosenbaum J, Prikazsky V (2002) Mortality in patients with proximal femoral fractures during the first year after the injury. Acta Chir Orthop Traumatol Cech 69(1):39-44 Czech

18. Chirodian N, Arch B, Parker MJ (2005) Sliding hip screw fixation of trochanteric hip fractures: outcome of 1024 procedures. Injury 36(6):793-800. Epub 2005 Apr. 20

19. Larsson S, Friberg S, Hansson LI (1990) Trochanteric fractures. Mobility, complications, and mortality in 607 cases treated with the sliding-screw technique. Clin Orthop Relat Res (260): 232-241 